\title{
Desvelando cercas: um olhar sobre a Educação do Campo no Sudeste do Tocantins
}

\author{
Thiago Ferreira dos Santos ${ }^{1}$, Idemar Vizolli ${ }^{2}$, Adriana Demite Stephani ${ }^{3}$ \\ ${ }^{1}$ Universidade Federal do Tocantins - UFT. Programa de Pós-Graduação em Educação. Campus Palmas. \\ Avenida NS 15, Quadra 109 Norte, s/n, Palmas - TO. Brasil. thiagoferreira@uft.edu.br. ${ }^{2}$ Universidade Federal \\ do Tocantins - UFT. ${ }^{3}$ Universidade Federal do Tocantins - UFT.
}

RESUMO. Vivemos numa época de mudanças na política, economia, ciência e tecnologia, o que tem gerado profundas transformações no modo de viver na sociedade. No entanto, o passado de abandono e isolamento no que tange a investimentos, infraestrutura e valorização ainda é latente em muitas escolas do espaço rural, o que demanda um olhar mais atento e crítico e a ampliação de pesquisas sobre essa questão. Assim, o presente estudo tem como objetivo mapear a realidade das escolas rurais das regionais de ensino de Arraias e Dianópolis localizadas no Sudeste do Tocantins, analisando sua atual situação. Para tanto, fez-se uso da pesquisa documental com uma abordagem predominantemente qualitativa para o trato e coleta de dados e informações disponíveis no acervo do Instituto Brasileiro de Geografia e Estatística (IBGE), Secretaria de Estado da Educação do Tocantins (SEDUC) e Ministério da Educação e Cultura (MEC). Além desses documentos, alguns autores embasaram nossas discussões sobre Educação do Campo: Arroyo, Caldart e Molina (2004), Caldart (2012), Kolling, Nery e Molina (1999), Nunes (2016), entre outros. Os resultados apontaram que ainda são frágeis as condições de atendimento educacional às populações que vivem no e do campo nas regionais estudadas, mesmo ante a ampliação das políticas públicas voltadas ao atendimento dos campesinos.

Palavras-chave: Educação do Campo, Escolas Rurais, Campo, Tocantins. 


\title{
Unveiling fences: a look at the Rural Education in the Southeast of Tocantins
}

\begin{abstract}
We live in a time of changes in politics, economics, science and technology, which has generated profound changes in the way of living in society. However, the past of abandonment and isolation regarding investments, infrastructure and valuation is still latent in many rural schools, which demands a closer and critical look and the expansion of research on this issue. Thus, the present study aims to map the reality of the rural schools of the regional schools of Arraias and Dianópolis located in the Southeast of Tocantins, analyzing their current situation. In order to do so, we used documentary research with a predominantly qualitative approach to the treatment and collection of data and information available in the collection of the Brazilian Institute of Geography and Statistics (IBGE), State Secretariat of Education of Tocantins (SEDUC) and Ministry Education and Culture (MEC). In addition to these documents, some authors have based our discussions on Field Education: Arroyo, Caldart and Molina (2004), Caldart (2012), Kolling, Nery and Molina (1999), Nunes (2016), among others. The results pointed out that the conditions of educational assistance to the populations living in the countryside are still fragile in the regions studied, even in the face of the expansion of public policies aimed at assisting peasants.
\end{abstract}

Keywords: Rural Education, Rural Schools, Countryside, Tocantins. 


\section{Develación vallas: una mirada a la Educación del Campo en el Sureste de Tocantins}

RESUMEN. Vivimos en una época de cambios en la política, la economía, la ciencia y la tecnología, que ha generado cambios profundos en la manera de vivir en sociedad. Sin embargo, el pasado de abandono y aislamiento con respecto a las inversiones, la infraestructura y la recuperación es todavía latente en muchas escuelas en las zonas rurales, lo que exige una mirada más cercana y la expansión de la crítica y la investigación en este tema. Por lo tanto, este estudio pretende trazar un mapa de la realidad de las escuelas rurales de Arraias y regional de la escuela Dianópolis ubicados en el sureste de Tocantins, el análisis de su situación actual. Por lo tanto, se hizo uso de la investigación documental con un enfoque cualitativo para el tratamiento y la recolección de los datos y la información disponible en la colección de Geografía y Estadística (IBGE) del Instituto Brasileño, Secretario de Estado de Tocantins Educación (SEDUC) y el Ministerio educación y Cultura (MEC). Además de estos documentos, algunos autores embasaram nuestras discusiones sobre Educación Rural: Arroyo, Caldart y Molina (2004), Caldart (2012), Kolling, Nery y Molina (1999), Nunes (2016), entre otros. Los resultados demostraron que siguen siendo frágiles condiciones de los servicios educativos a las personas que viven en el campo y en el estudio regional, incluso antes de la expansión de las políticas públicas destinadas a satisfacer los campesinos.

Palabras clave: Educación Rural, Las Escuelas Rurales, El Campo, Tocantins. 


\section{Abrindo estradas}

Nos últimos vinte anos, temos assistido a uma grande e marcante presença dos sujeitos do campo nas cenas política e cultural do país. Seus processos de formação passaram a ser objeto de pesquisas nas universidades, agências internacionais, governos e dos diversos movimentos sociais. Milhares de educadores estão se mobilizando, debatendo e buscando refazer concepções e práticas educativas em escolas de comunidades camponesas, em escolas família-agrícola, escolas de assentamentos, escolas de atingidos por barragens, escolas em comunidades ribeirinhas, escolas de comunidades indígenas e quilombolas, dentre outras (Arroyo, Caldart \& Molina, 2004).

No entanto, o interesse no estudo sobre a educação dos povos do campo nem sempre existiu e, por longa data, tais povos foram "silenciados" nas pesquisas sociais e educacionais, histórico considerado preocupante pelos pesquisadores Arroyo, Caldart e Molina (2004). Segundo os autores, "somente $2 \%$ das pesquisas diziam respeito a questões do campo", não chegando a $1 \%$ as que se referiam à educação básica dos campesinos. Logo, o movimento em busca de uma educação do campo de qualidade surgiu com a intenção de denunciar este esquecimento por partes dos órgãos governamentais, centros de pesquisas e estudiosos de questões sociais e educacionais (Arroyo, Caldart \& Molina, 2004).

$\mathrm{Na}$ perspectiva de contribuir com as análises e reflexões sobre a educação ofertada aos campesinos, nos desafiamos a analisar a realidade das escolas localizadas nas áreas rurais dos municípios das regionais de ensino do Sudeste do Estado do Tocantins. A escolha desse lócus se deve ao fato da existência de uma considerável população campesina nessa região. Para tanto, estabelecemos como objetivos específicos: identificar as escolas das áreas rurais em funcionamento; verificar o quantitativo de estudantes matriculados; analisar as condições estruturais físicas e de material, assim como de atendimento aos estudantes; e identificar os projetos de formação docente.

\section{Derrubando cercas}

Ao derrubar as cercas direcionamos nosso estudo às questões epistemológicas, históricas e conceituais da educação do campo. Para Caldart (2012), a Educação do Campo descreve um fenômeno da 
realidade brasileira, protagonizado pelos trabalhadores do campo e suas organizações, que visa incidir sobre a política de educação e os interesses sociais das comunidades camponesas, no que tange às questões referentes a trabalho, cultura, conhecimento e lutas sociais dos camponeses e ao embate (de classe) entre projetos de campo e lógicas de agricultura que têm implicações no projeto de país e de sociedade (Caldart, 2012).

\section{Educação do Campo: dos movimentos à terminologia}

A expressão "Educação do Campo", antes denominada de Educação Básica do Campo, nasceu por ocasião da ocorrência da I Conferência Nacional por uma Educação Básica do Campo. Evento este realizado em Goiás, na cidade de Luziânia, no período de 27 a 30 de julho de 1998. E, a partir das discussões do Seminário Nacional realizado entre 26 a 29 de novembro de 2002 em Brasília, passouse a ser chamada de Educação do Campo. Decisão esta posteriormente reafirmada nos debates da II Conferência Nacional, realizada em julho de 2004 (Caldart, 2012).

De acordo com a Caldart (op cit), em 1997 foram iniciadas as discussões para a realização da I Conferência, o que ocorreu após o I Encontro Nacional dos Educadores e Educadoras da Reforma Agrária (ENERA), realizado pelo Movimento dos Trabalhadores Rurais Sem Terra (MST) em julho daquele ano. Tal evento culminou no desafio para o MST de discutir a educação no meio rural do Brasil, sendo instituído ainda pelo governo federal em 16 de abril de 1998 o Programa Nacional de Educação na Reforma Agrária (PRONERA). Oportuno destacar que nas discussões de preparação do documento base da I Conferência, concluído em maio de 1998 e debatido nos encontros estaduais que antecederam o evento nacional, estão os argumentos do batismo do que representaria ao que no Brasil se denominava até então de Educação Rural (Caldart, 2012).

De acordo com as pesquisas de Kolling, Nery e Molina (1999, p. 26), passa-se a usar,

... a expressão campo, e não a mais usual, meio rural, com o objetivo de incluir no processo da conferência uma reflexão sobre o sentido atual do trabalho camponês e das lutas sociais e culturais dos grupos que hoje tentam garantir a sobrevivência desse trabalho. Mas, quando se discutir a educação do campo, se estará tratando da educação que se volta ao conjunto dos 
trabalhadores e das trabalhadoras do campo, sejam os camponeses, incluindo os quilombolas, sejam as nações indígenas, sejam os diversos tipos de assalariados vinculados à vida e ao trabalho no meio rural. Embora com essa preocupação mais ampla, há uma preocupação especial com $\mathrm{O}$ resgate do conceito de camponês. Um conceito histórico e político... (Kolling, Nery \& Molina, 1999, p. 26).

Dentre os esforços para constituirse a Educação do Campo - e que ainda obteve resultados relativos - estão as lutas pela transformação da realidade educacional específica das áreas de Reforma Agrária, articulando-se a isso experiências históricas de luta e resistência, como as das Escolas Família Agrícola (EFA), do Movimento de Educação de Base (MEB), das organizações indígenas e quilombolas, do Movimento dos Atingidos por Barragens (MAB), de organizações sindicais, de diferentes comunidades e escolas rurais (Caldart, 2012).

Nesse processo de discussão e formulação de uma identidade do movimento pró-educação campesina, em julho de 2004 realizou-se a II Conferência Nacional por uma Educação do Campo:

O lema formulado na II Conferência Nacional, "Educação do Campo: direito nosso, dever do Estado!", expressou entendimento comum possível naquele momento: a luta pelo acesso dos trabalhadores do campo à educação é específica, necessária e justa, deve se dar no âmbito do espaço público, e o Estado deve ser pressionado para formular políticas que a garantam massivamente, levando à universalização real e não apenas princípio abstrato. Em meio aos debates, às vezes acirrados, ficou reafirmada a posição originária de vínculo da Educação do Campo com o polo do trabalho, o que significa assumir o confronto de projetos, e desde os interesses da agricultura camponesa. (Caldart, 2012, p. 262).

Dando continuidade as discussões e organizações campesinas, no ano de 2010 foi criado o Fórum Nacional de Educação do Campo (FONEC), objetivando retomar a atuação articulada de diferentes movimentos sociais, organizações sindicais e outras instituições, agora com a participação mais ampliada de universidades e institutos federais de educação. $\mathrm{O}$ FONEC tomou posição contrária ao fechamento de escolas do campo, inserindo em suas pautas a luta pela ampliação do quantitativo de escolas no campo, assim como, a ampliação do nível de escolarização da população campesina, assumindo o compromisso coletivo de contraponto ao agronegócio e de combate à criminalização dos movimentos sociais (Caldart, 2012). Diante desses avanços e conquistas, 
pode-se afirmar que a Educação do Campo ainda está em processo de construção e já possui algumas características próprias que podem identificá-la:

- Constitui-se como luta social pelo acesso dos trabalhadores do campo à educação (e não a qualquer educação) feita por eles mesmos e não apenas em seu nome. A Educação do Campo não é para nem apenas com, mas sim, dos camponeses, expressão legítima de uma pedagogia do oprimido.

- Assume a dimensão de pressão coletiva por políticas públicas mais abrangentes ou mesmo de embate entre diferentes lógicas de formulação e de implementação da política educacional brasileira. Faz isso sem deixar de ser luta pelo acesso à educação em cada local ou situação particular dos grupos sociais que a compõem, materialidade que permite a consciência coletiva do direito e a compreensão das razões sociais que o impedem.

- Combina luta pela educação com luta pela terra, pela Reforma Agrária, pelo direito ao trabalho, à cultura, à soberania alimentar, ao território. Por isso, sua relação de origem com os movimentos sociais de trabalhadores. $\mathrm{Na}$ lógica de seus sujeitos e suas relações, uma política de Educação do Campo nunca será somente de educação em si mesma... (Caldart, 2012, p. 263).

Essas características apontadas por Cadart (2012) já vislumbram o espaço que a Educação do Campo pode alcançar. Suas práticas visam reconhecer e trabalhar com a riqueza social e humana da diversidade de seus sujeitos, com suas formas singulares de trabalho, raízes e produções culturais, formas de luta, de resistência, de organização, de compreensão política, de modo de vida.

\section{A Educação Básica do Campo}

O movimento de lutas e debates que fomentou a discussão de uma educação voltada aos povos campesinos começou a colher frutos nos anos finais da década de 1980. E, para se compreender o cenário da educação básica do campo em meio à luta política pelos direitos humanos nas áreas rurais do Brasil (sertões, interior, campo, rincões), diante da diversidade de projetos, há que se buscar elementos, eventos, processos e movimentos que contribuam para a constituição dessa realidade (Oliveira \& Campos, 2012).

Ao discutirem e analisarem o contexto de solidificação desse movimento, Oliveira e Campos (2012, p. 239), destacam que:

O contexto educacional recente do mundo rural vem sendo transformado por movimentos instituintes que começaram a se articular no final dos anos 1980 , quando a sociedade civil brasileira vivenciava o processo de saída do regime militar, participando da organização de espaços públicos e de lutas 
democráticas em prol de vários direitos, dentre eles, a educação do campo. A educação, como direito de todos ao acesso e à permanência na escola...

O recomeço pelo qual o país passava na década de 1980 se fez oportuno para a retomada de algumas discussões em relação aos direitos humanos, inclusive a educação e também abriu espaço para as discussões sobre a educação Campesina, isso porque,

...a educação básica é um conceito avançado e inovador para o Brasil, na medida em que se instituiu em meio à efervescência de propostas reivindicadas pelos movimentos, ao mesmo tempo em que se tornava um bem público e ampliava o campo dos direitos. Compreendida assim, a educação básica necessita de políticas de universalização para se tornar efetivamente um direito de todos, inclusive dos povos do campo, para que os profissionais da educação e os usuários das instituições escolares se formem assegurando suas territorialidades e identidades sociais. (Oliveira \& Campos, 2012, p. 240).

No I ENERA foram indicadas as primeiras e mais marcantes insatisfações do Movimento dos Trabalhadores Rurais Sem Terra (MST), de outros atores políticos e de instituições universitárias e científicas, em relação a educação destinada às crianças, aos jovens e adultos dos sertões/campo brasileiros (Kolling,

Nery \& Molina, 1999).

Para Kolling, Nery e Molina (1999), a rebeldia sempre foi traduzida em vontade de emancipação das diversas populações hoje intituladas do campo (campesinas, indígenas, caiçaras, quilombolas, atingidas por barragens, de agricultores), que buscam a educação a partir de uma perspectiva contrahegemônica. Foi justamente esse fato que trouxe a diferenciação da Educação do Campo da histórica "educação rural": o protagonismo dos movimentos sociais do campo na negociação de políticas educacionais, postulando nova concepção de educação que incluísse suas cosmologias, lutas, territorialidades, concepções de natureza e família, arte, práticas de produção, bem como, a organização social e o trabalho.

Na continuidade do movimento,

[as] conferências - assim como os fóruns - por uma "Educação Básica do Campo" se sucederam da década de 1990 até a década atual, tornando-se espaços de produção de conhecimento e de articulação de saberes, cuja essencialidade denota a participação campesina na construção de um ideário políticopedagógico e de diretrizes operacionais que orientem as políticas públicas para a educação do campo. Visando responder às demandas dos movimentos sociais do campo que, desde o final da 
década de 1990, se arrastavam no Conselho Nacional de Educação (CNE), surgem, no contexto educacional da década seguinte, $o$ parecer $\mathrm{n}^{\circ} 36$, de 2001, e a resolução $\mathrm{n}^{\circ} 1$ (3 de abril de 2002 - "Diretrizes operacionais da educação do campo"). (Oliveira \& Campos, 2012, p. 240).

Em 2004, foi criada a Secretaria de Educação Continuada, Alfabetização e Diversidade (SECADI) no âmbito do Ministério da Educação (MEC) que possuía, entre as suas funções, a de buscar a diversidade cultural $\mathrm{e}$ as experiências de educação e de desenvolvimento das regiões, a fim de ampliar a oferta de educação básica e de EJA nas escolas rurais e assentamentos do Instituto Nacional de Colonização e Reforma Agrária (INCRA). (Oliveira \& Campos, 2012).

No entanto, "[a]pesar de os dados da educação do campo serem reconfigurados em função das lutas, ainda permanecem deficiências grandes, tais como a falta de atendimento no âmbito da educação infantil, do segundo segmento do ensino fundamental, do ensino médio e do ensino superior, além das modalidades de EJA e educação especial". (Oliveira \& Campos, 2012, p. 242).

Refletindo sobre os desafios que os povos campesinos enfrentam,
Oliveira e Campos (2012, p. 244-245) assim se posicionam:

Agricultores familiares, quilombolas, sem-terra, indígenas, mestiços, agricultores urbanos, juventude rural e outras formas identitárias, sujeitos que buscam afirmar seus pertencimentos sociais como "povos do campo" encontram como principais desafios para a consolidação da educação básica do campo: a ampliação da educação infantil, do segundo segmento do ensino fundamental e do ensino médio para os sujeitos do campo; a luta contra o fechamento das escolas do campo; o investimento na formação inicial e continuada de educadores do campo; a construção de materiais didáticos contextualizados e a implementação de metodologias ativas e participativas; o investimento na formação dos gestores das escolas do campo; a implementação da pedagogia da alternância nas escolas do campo, referenciando-a em documentos oficiais (planos municipais e estaduais de educação); a constituição de coordenações de Educação do Campo no âmbito das secretarias municipais e estaduais de Educação; a institucionalização de diretrizes de Educação do Campo no âmbito dos planos municipais e estaduais de Educação; e a abertura de concursos públicos específicos.

Diante dessa breve retomada de fatos e eventos que ajudaram a solidificar a defesa de uma verdadeira "Educação do Campo", podemos verificar que muitas foram as conquistas nas últimas duas décadas. No entanto, os avanços ainda são relativos e 
mudanças ainda são necessárias para que haja de fato uma educação de qualidade para os povos que vivem no e do campo. O que temos ainda, em muitos espaços é uma educação em escolas localizadas no campo, rurais ${ }^{\mathrm{i}}$, e não para o campo e do campo.

\section{O lócus da pesquisa}

Objetivamos aqui trazer dados e informações de um lócus específico, a região Sudeste do Estado do Tocantins, que possuí singularidades em relação a sua localização geográfica e à demarcação territorial. Dessa forma, para entendermos algumas dessas particularidades, faz-se oportuno trazer dados de sua constituição, que possuem nuances que elucidam a situação do ensino nesse espaço geográfico. A região Sudeste do Tocantins, administrativamente, é composta por 21 (vinte e um municípios) dentre os 139 (cento e trinta e nove) que compõem o Estado. No presente estudo, optou-se por analisar a realidade da educação das escolas localizadas no espaço rural nas regionais de ensino de Arraias e Dianópolis, as quais abarcam 15 (quinze) municípios. O quadro 1 , a seguir, indica os municípios de abrangência de cada uma das regiões e sua respectiva população.

\begin{tabular}{|c|c|c|}
\hline $\begin{array}{l}\text { NOME DA DIRETORIA REGIONAL DE } \\
\text { ENSINO }\end{array}$ & MUNICÍPIO VINCULADO & POPULAÇÃO 2015* \\
\hline \multirow{6}{*}{ ARRAIAS } & Arraias & 10.778 \\
\hline & Aurora do Tocantins & 3.682 \\
\hline & Combinado & 4.851 \\
\hline & Lavandeira & 1.814 \\
\hline & Novo Alegre & 2.351 \\
\hline & Paranã & 10.573 \\
\hline \multirow{9}{*}{ DIANOPOLIS } & Almas & 7.409 \\
\hline & Conceição do Tocantins & 4.209 \\
\hline & Dianópolis & 21.167 \\
\hline & Novo Jardim & 2.650 \\
\hline & Ponte Alta do Bom Jesus & 4.649 \\
\hline & Porto Alegre do Tocantins & 3.039 \\
\hline & Rio da Conceição & 1.980 \\
\hline & Taguatinga & 16.238 \\
\hline & Taipas do Tocantins & 2.094 \\
\hline
\end{tabular}

Quadro 1 - Regionais de ensino localizadas no Sudeste do Tocantins. Fonte: Adaptado de Tocantins (2015). 
Os dados demonstram que a população da regional de Arraias é de 34.049 (trinta e quatro mil e quarenta e nove) habitantes e da regional de Dianópolis é de 63.435 (sessenta e três mil quatrocentos e trinta e cinco), o que correspondem, respectivamente, a $2,22 \%$ e 4,13\% da população do Estado ${ }^{\text {ii }}$.

O Sudeste do Tocantins possui aproximadamente 123.791 (cento e vinte e três mil setecentos e noventa e um mil) habitantes, dos quais 88.703 (oitenta e oito mil setecentos e três) residem na zona urbana e 35.088 (trinta e cinco mil e oitenta e oito) residem no campo - aproximadamente $29 \%$ dos habitantes da região (Brasil, 2015).

Analisando os censos demográficos do Sudeste do Tocantins de 2000 a 2010, nota-se que houve um aumento de sua população, de 117.456 para 123.791 habitantes, uma variação de $5,12 \%$. Neste interstício, houve uma redução de $23,69 \%$ na população que vive no campo (Brasil, 2015). Acreditase que as questões políticas tiveram grande influência na migração, especialmente porque a região conta com uma grande quantidade de pessoas em vulnerabilidade socioeconômica, que na intenção de obtenção de melhores condições de vida passam a residir na cidade.

Ainda, os municípios de Combinado e Paranã, possuem, respectivamente, a menor e maior taxa de pessoas extremamente pobres, $4,18 \%$ e 31,89\% nesta região (Brasil, 2015). Em relação a pessoas em situação de vulnerabilidade à pobreza, destacam-se, respectivamente, os municípios de Rio da Conceição e Paranã, com maior e menor taxas, correspondendo a $91,40 \%$ e $55,15 \%$.

Importante salientar que grande parte da economia da região sudeste do Tocantins é proveniente da lavoura e da pecuária, sobretudo da agricultura familiar. Contando com 6.376 (seis mil trezentos e setenta e seis) estabelecimentos de agricultura familiar agrupando um total de 18.687 (dezoito mil seiscentos e oitenta e sete) pessoas, o que corresponde a $15 \%$ da sua população. Os municípios de Taguatinga e Taipas do Tocantins, respectivamente, destacam-se, com o maior e menor número de propriedades de agricultura familiar: 789 (setecentos e oitenta e nove) e 41 (quarenta e um) estabelecimentos. No tocante ao número de pessoas envolvidas na agricultura familiar, destacam-se, respectivamente, Paranã e Rio da Conceição com o maior 
e menor número, correspondendo a

2.849 (dois mil oitocentos e quarenta e nove) e 84 (oitenta e quatro) pessoas (Brasil, 2015).

Diante dessa conjuntura, faz-se imprescindível a realização de pesquisas que elucidem a realidade das escolas rurais dessa região localizadas no campo, no intento também de coletar dados que possam ser utilizados na proposição de alternativas e estratégias para que realmente o direito à educação aos povos do campo se efetive.

\section{Construindo caminhos}

Para desenvolvimento do presente estudo fez-se uso da pesquisa documental com uma abordagem predominantemente qualitativa para $\mathrm{o}$ trato e coleta de dados. "A ideia de se incluir o estudo de documentos enquanto possibilidade da pesquisa qualitativa pode, à primeira vista, parecer estranha..." (Godoy, 1995, p. 21); porém:

...a abordagem qualitativa, enquanto exercício de pesquisa, não se apresenta como uma proposta rigidamente estruturada, ela permite que a imaginação e a criatividade levem os investigadores a propor trabalhos que explorem novos enfoques. Nesse sentido, acreditamos que a pesquisa documental representa uma forma que pode se revestir de um caráter inovador, trazendo contribuições importantes no estudo de alguns temas. Além disso, os documentos normalmente são considerados importantes fontes de dados para outros tipos de estudos qualitativos, merecendo, portanto atenção especial. (Godoy, 1995, p. 21).

Dessa forma, estruturou-se o presente trabalho em quatro etapas: levantamento de bibliografias relacionadas (a educação do campo, a educação básica do campo e o contexto da pesquisa); coleta de informações junto a documentos disponíveis em leis, resoluções e levantamentos impressos das Secretarias de Estado de Educação do Tocantins (SEDUC), Instituto Brasileiro de Geografia e Estatística (IBGE) e Ministério da Educação e Cultura (MEC); sistematização das informações coletadas nos documentos; análise e discussão das informações.

\section{Conhecendo a terra em que pisamos}

Ao conhecer a terra em que pisamos, nos desafiamos a desvendar a realidade da Educação ofertada aos campesinos nas regionais de Ensino de Arraias e Dianópolis, tendo como fio condutor das reflexões os objetivos estabelecidos no presente estudo. 
A realidade das escolas rurais nas regionais de ensino de Arraias e Dianópolis

A regional de ensino de Arraias conta com 42 (quarenta e duas) escolas localizadas no meio rural, sendo 04 (quatro) administradas pelo Governo do
Estado e as demais pelo Poder Executivo de cada município. O gráfico 1, a seguir, apresenta a quantidade de matrículas desta regional nas suas respectivas unidades escolares nas diversas fases da sua Educação Básica.

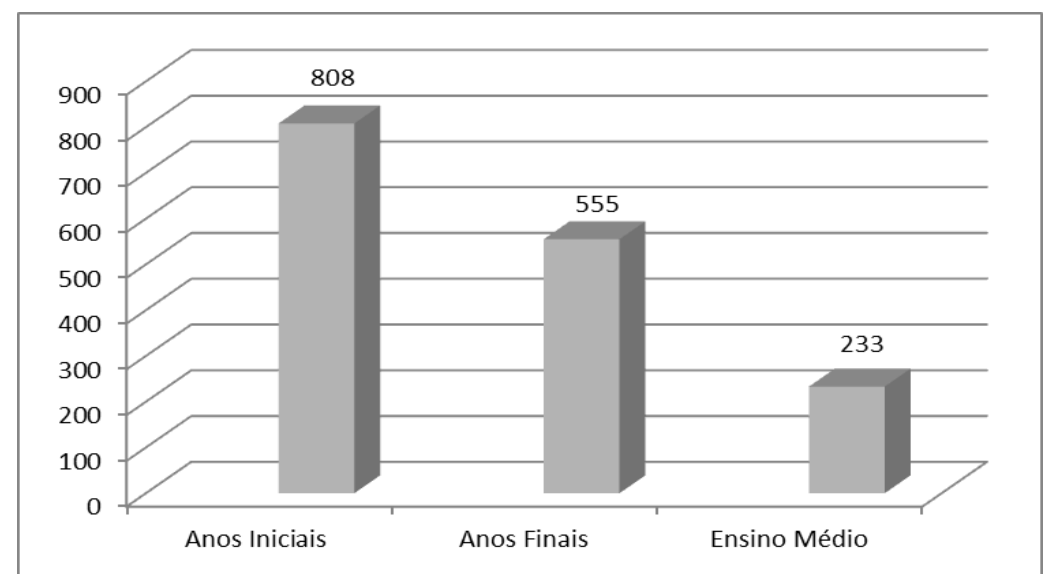

Gráfico 1 - Número de matrículas na Educação Básica em escolas rurais - Regional de Arraias/2015. Fonte: Adaptado de Tocantins (2015).

Ressalta-se que a maioria das Unidades Escolares que atendem estudantes dos Anos Iniciais do Ensino Fundamental é mantida pelo governo dos respectivos municípios. Menos da metade das escolas desta regional atende estudantes do segundo segmento do Ensino Fundamental e, somente 04 (quatro) delas, atendem a estudantes do Ensino Médio, sendo mantidas pelo Governo do Estado, registrando-se a efetivação de 233 (duzentos e trinta e três) matrículas.

$\mathrm{Na}$ regional de ensino de Dianópolis encontram-se 43 (quarenta e três) escolas localizadas no meio rural. Destas, 39 (trinta e nove) são mantidas pelo Poder Executivo dos respectivos municípios, 03 (três) pelo Governo do Estado e 01 (uma) pelo Governo Federal. O gráfico 2 indica a quantidade de matrículas na Educação Básica: 


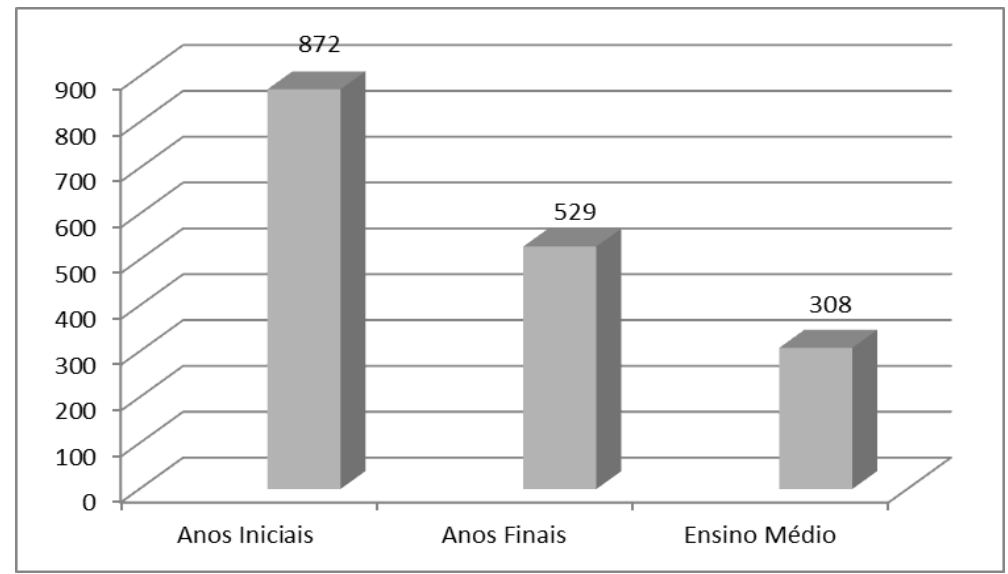

Gráfico 2 - Número de matrículas na Educação Básica em escolas rurais - Regional de Dianópolis/2015. Fonte: Adaptado de Tocantins (2015).

Das escolas do meio rural desta regional, apenas 04 (quatro) atendem ao Ensino Médio, sendo que 02 (duas) delas integram cursos técnicos (Colégio Agropecuário de Almas - curso de agropecuária; e Instituto Federal de Ciência e Tecnologia de Dianópolis curso de informática). Em 2015 foram realizadas 235 (duzentas e trinta e cinco) matrículas em cursos de Ensino Médio integrados a cursos técnicos. Assim, como na regional de Arraias, na regional de Dianópolis prevalece o número de escolas e matrículas nos Anos Inicias do Ensino Fundamental, em escolas mantidas pelo poder público municipal, mas figuram, no meio rural, escolas técnicas.

A realidade mostra que as redes municipais de ensino atendem prioritariamente a Educação Infantil e os Anos Iniciais do Ensino Fundamental; e, a rede estadual atende prioritariamente as séries finais do Ensino Fundamental ( $6^{\circ}$ ao $9^{\circ}$ anos $)$ e Ensino Médio.

Sob a ideia contrária de que a educação é investimento, mais precisamente, na concepção de muitos administradores públicos que a concebe como gasto, o processo de municipalização do ensino impulsionou o fechamento de muitas escolas nas regiões rurais, o que gerou mais prejuízos aos camponeses, especialmente aos estudantes, isso porque necessitam se deslocar até a sede dos municípios para continuarem seus estudos.

O transporte escolar ofertado para esses estudantes tem servido como justificativa para o acesso ao processo de escolarização. Esquece-se, no entanto, que o deslocamento do estudantes para outra localidade, que não sua comunidade, gera uma série de 
problemas, iniciando pelo distanciamento da criança ou adolescente de seus familiares, perpassando pela adaptação ao novo ambiente, diferente de seu lugar de origem.

As dificuldades oriundas da estrutura técnico-administrativa e financeira dos municípios das regionais pesquisadas gera a necessidade de alocação de recursos complementares à educação, mais precisamente ao transporte escolar, o que muitas vezes é viabilizado por meio de projetos conveniados com o Ministério da Educação e Cultura (MEC) e outras instituições.

Outro fator que merece atenção é a quantidade de matrículas de estudantes com necessidades especiais nas escolas do meio rural (Tabela 1). Na regional de Arraias, o número de matrículas correspondeu a $6,13 \%$ do total e na regional de Dianópolis, o percentual foi de $3,94 \%$.

\begin{tabular}{|ccc|}
$\begin{array}{c}\text { TIPO DE NECESSIDADE } \\
\text { ESPECIAL }\end{array}$ & $\begin{array}{c}\text { REGIONAL } \\
\text { ARRAIAS }\end{array}$ & $\begin{array}{c}\text { REGIONAL } \\
\text { DIANOPOLIS }\end{array}$ \\
\hline Surdez & 06 & Nenhum \\
\hline Baixa visão & 08 & 06 \\
\hline Necessidade Especial & 51 & 29 \\
\hline Deficiência física & 02 & 05 \\
\hline Deficiência múltipla & 01 & Nenhum \\
\hline Deficiência intelectual & 33 & 17 \\
\hline Síndrome Asperger & 02 & Nenhum \\
\hline $\begin{array}{c}\text { Transtorno Desintegrativo } \\
\text { Infantil }\end{array}$ & 01 & 01 \\
\hline
\end{tabular}

Tabela 1 - Número de matrículas segundo o tipo de deficiência por Regional/2015. Fonte: Adaptado de Tocantins (2015).

O quantitativo de estudantes com necessidades especiais no meio rural demonstra a necessidade de os programas de formação na área de Educação inserirem em seus cursos a temática da Educação Especial.

\section{Infraestrutura das Unidades Escolares rurais nas regionais de Arraias e Dianópolis}

$\mathrm{Na}$ Tabela 2, a seguir, apresentamos informações relevantes em relação a estrutura física existente nas escolas rurais localizadas nas regionais estudadas, focando especialmente nos espaços de ensino, convivência, suporte administrativo e/ou pedagógico. 


\begin{tabular}{|c|c|c|}
\hline $\begin{array}{l}\text { ESTRUTURA FÍSICA DAS UNIDADES } \\
\text { ESCOLARES }\end{array}$ & $\begin{array}{l}\text { REGIONAL } \\
\text { ARRAIAS }\end{array}$ & $\begin{array}{l}\text { REGIONAL } \\
\text { DIANOPOLIS }\end{array}$ \\
\hline Sala de diretoria & 04 & 09 \\
\hline Sala de professores & 08 & 16 \\
\hline Laboratório de informática & 05 & 11 \\
\hline Laboratório de ciências & 01 & 02 \\
\hline Sala de atendimento especial & 02 & 03 \\
\hline Quadra de esportes coberta & 02 & 02 \\
\hline Quadra de esportes descoberta & 02 & 03 \\
\hline Cozinha & 35 & 42 \\
\hline Biblioteca & 01 & 06 \\
\hline Sala de leitura & 02 & 05 \\
\hline Biblioteca ou sala de leitura & 03 & 09 \\
\hline Parque infantil & Nenhum & 01 \\
\hline Berçário & Nenhum & Nenhum \\
\hline Banheiro fora do prédio & 11 & 13 \\
\hline Banheiro dentro do prédio & 15 & 19 \\
\hline Banheiro adequado à educação infantil & Nenhum & Nenhum \\
\hline $\begin{array}{l}\text { Banheiro adequado à estudantes com deficiência ou } \\
\text { mobilidade reduzida }\end{array}$ & Nenhum & 01 \\
\hline $\begin{array}{c}\text { Dependências e vias adequadas a estudantes com } \\
\text { deficiência ou mobilidade reduzida }\end{array}$ & 01 & 02 \\
\hline Secretaria & 08 & 06 \\
\hline Banheiro com chuveiro & 02 & 12 \\
\hline Refeitório & 01 & 01 \\
\hline Despensa & 06 & 15 \\
\hline Almoxarifado & 02 & 04 \\
\hline Auditório & Nenhum & 01 \\
\hline Pátio coberto & 03 & 05 \\
\hline Pátio descoberto & 01 & 10 \\
\hline Alojamento para estudantes & 01 & 01 \\
\hline Alojamento para professores & Nenhum & 04 \\
\hline Área verde & 03 & 13 \\
\hline Lavanderia & 01 & 01 \\
\hline Total de salas de aula para atendimento aos discentes & 105 & 135 \\
\hline
\end{tabular}

Tabela 2 - Infraestrutura das escolas rurais das regionais de Arraias e Dianópolis/2015. Fonte: Adaptado de Tocantins (2015).

Os dados apontados na tabela anterior indicam os espaços escolares além da sala de aula. Se pudéssemos aqui registrar, via os bancos de dados consultados para pesquisa, o que concerne a sala de aula, poderíamos nos espantar pois, a realidade de infraestrutura é preocupante. Ainda é possível encontrar unidades escolares que não dispõem nem mesmo de carteiras em número suficiente para seus estudantes, muitas vezes 
acomodados em bancos de madeira improvisados.

Essa realidade apontada no que se refere a infraestrutura das escolas do meio rural é o recorrente em todo o país e provoca uma submissão a situações muito degradantes (Alves, 2009), que afastam e dificultam a consolidação da tão almejada Educação do Campo iii.

Em relação a equipamentos de tecnologia, constata-se que nas escolas rurais do país a realidade é bastante aterradora, visto que apenas $0,5 \%$ destas escolas contam com computadores. Dados estes que possibilitam uma melhor compreensão da situação de penúria a que está submetido o estudante campesino (Alves, 2009). Na Tabela 3, a seguir, consta a situação das regionais de Arraias e Dianópolis:

\begin{tabular}{|ccc|}
\hline $\begin{array}{c}\text { EQUIPAMENTOS DE } \\
\text { TECNOLOGIA }\end{array}$ & $\begin{array}{c}\text { REGIONAL } \\
\text { ARRAIAS }\end{array}$ & $\begin{array}{c}\text { REGIONAL } \\
\text { DIANOPOLIS }\end{array}$ \\
\hline TV & 21 & 35 \\
\hline Videocassete & 01 & 04 \\
\hline DVD & 20 & 27 \\
\hline Antena parabólica & 13 & 08 \\
\hline Copiadora & 01 & 19 \\
\hline Retroprojetor & 04 & 05 \\
\hline Impressora & 10 & 32 \\
\hline Impressora multifuncional & 01 & 10 \\
\hline Aparelho de som & 10 & 24 \\
\hline Projetor multimídia & 09 & 15 \\
\hline Aparelho de fax & Nenhum & 01 \\
\hline Máquina fotográfica ou filmadora & 08 & 19 \\
\hline Computadores na escola & 69 & 170 \\
\hline Computador administrativo & 08 & 80 \\
\hline
\end{tabular}

Tabela 3 - Equipamentos de tecnologia por Regional/2015. Fonte: Adaptado de Tocantins (2015).

Ressalta-se que a falta de energia elétrica (especialmente na regional de Arraias), inviabiliza a instalação e/ou utilização de uma série de equipamentos. Outras, ainda que tendo energia elétrica, devido à localização, ficam impedidas da conexão à internet. $\mathrm{O}$ uso de computadores restringe-se quase que exclusivamente ao administrativo e, quando utilizados para fỉns pedagógicos, são realizadas apenas demonstrações de ferramentas 
instaladas nessas máquinas. Ou seja, os computadores dificilmente são utilizados para fins de pesquisas, leitura, busca de informações e consultas em sites educativos, por exemplo.

\section{Projetos de Formação Docente}

Dentre os programas de formação continuada para profissionais das escolas rurais do Estado do Tocantins, destacam-se Escola Ativa e Circuito Campeão no ano de 2012 e, o Programa Pacto de Alfabetização na Idade Certa, em 2013 (Nunes, 2016).

O programa Escola Ativa teve como objetivo a melhoria da qualidade do desempenho escolar em classes multisseriadas; isto a partir da formação de professores e uso de recursos pedagógicos que estimulem a construção do conhecimento pelo estudante (Brasil, 2010). O Programa Circuito Campeão visou a melhoria da qualidade do ensino dos anos iniciais da rede pública, valendo-se da implantação de processos gerenciais e pedagógicos e do acompanhamento sistêmico do alcance das metas e indicadores definidos (Tocantins, 2012). Já o Programa Pacto de Alfabetização em Idade Certa tem como objetivo assegurar que todas as crianças sejam alfabetizadas até os oito anos de idade, ao final do $3^{\circ}$ ano do ensino fundamental (Brasil, 2016).

\section{Mapeando novos rumos}

As discussões aqui apresentadas não tiveram a pretensão de esmiuçar todos os elementos constituintes da realidade das escolas rurais das regionais de ensino de Arraias e Dianópolis mas, sim, trazer alguns aspectos importantes e carentes de análise dentro deste cenário.

Embora estas regionais contem com um número significativo de unidades escolares em funcionamento no meio rural, percebe-se que ainda falta a ampliação da oferta, de modo que todas as pessoas possam concluir a Educação Básica e tenham a possibilidade de ingressar no ensino superior. Registra-se, no entanto, que os municípios de Aurora do Tocantins, Combinado, Lavandeira e Novo Alegre, ambos da regional de Arraias, contam somente com escolas na sede do município e a reduzida quantidade em outros, o que denota a falta de preocupação com a Educação do Campo, no campo e para o campo, conforme os termos da legislação ${ }^{\text {iv }}$.

Muitas escolas do meio rural carecem de melhorias substanciais em sua infraestrutura física, haja vista a 
existência de escolas que não possuem forro, piso em cimento bruto; escolas construídas em adobe (tijolo de barro secado ao sol) e com coberturas de palha (folhas de palmeiras). Muitas escolas não contam com carteiras e cadeiras suficientes para atender a demanda dos estudantes; faltam armários, quadros e demais equipamentos e materiais básicos e essenciais para o desenvolvimento das atividades pedagógicas.

O fechamento de escolas, aliado à precariedade no transporte dos estudantes para escolas localizadas na sede do município, vem ocasionando uma série de problemas que culminam com o abandono da escolarização quando ainda crianças ou jovens, elevando com isso os índices de analfabetos funcionais e gerando a necessidade da Educação de Jovens e Adultos que, ao ser ofertada, muitas vezes o grau de precariedade se eleva.

Ao considerarmos que se tratam de regionais com características essencialmente agrícolas, essa problemática se torna ainda mais preocupante, especialmente porque não se vê materializadas políticas públicas específicas para a população campesina, sobretudo aquela que se encontra em situação de vulnerabilidade socioeconômica, como é o caso de uma série de municípios do Estado do Tocantins, inclusive das regionais em estudo.

A realidade da educação do campo passou a ser desnudada a partir das lutas dos movimentos sociais e começou a ter força a partir da instituição de políticas públicas específicas, o que geraram avanços importantes, mas a realidade ainda mostra a fragilidade em que se encontra o processo de ensino e aprendizagem nas escolas rurais e o quanto ainda é necessário se fazer no sentido de instrumentalizar e empoderar os campesinos, a fim de que possam lutar para que seus direitos sejam garantidos de fato.

\section{Referências}

Alves, G. L. (Org.). (2009). Educação no campo recortes no tempo e no espaço. Campinas, SP: Autores Associados.

Arroyo, M. G., Caldart, R. S., \& Molina, M. C. (Org.). (2004). Por uma educação do campo. Petrópolis, RJ: Vozes.

Brasil. (1996). Lei $n^{o}$ 9.394, de 20 de dezembro de 1996. Estabelece as diretrizes e bases da educação nacional. Recuperado em 02 de setembro, 2016, de http://www.planalto.gov.br. . (2002). Resolução CEB/MEC $n^{o}$ 001, de 03 de abril de 2002. Institui 
Diretrizes Operacionais para a Educação Básica nas escolas do campo. Recuperado em 06 de setembro, 2016, de http://www.portal.mec.gov.br.

(2010). Ministério da Educação, Secretaria de Educação Continuada, Alfabetização e Diversidade. Escola Ativa - Projeto Base. Brasília. . (2015). Caderno Territorial Sudeste do Tocantins/CGMA. Brasília.

\begin{tabular}{cccc} 
& (2016). & Ministério da \\
\hline Educação. & Pacto & Nacional pela
\end{tabular} Alfabetização em Idade Certa. Brasília. Recuperado em 09 de novembro, 2016, de http://pacto.mec.gov.br/2uncategorised/53-entendento-o-pacto.

Caldart, R. S. (2012). Educação do Campo. In Caldart, R.S., Pereira, I. B., Alentejano, P., \& Frigotto, G. (Org.). Dicionário da Educação do Campo. Rio de Janeiro, São Paulo: Escola Politécnica de Saúde Joaquim Venâncio, Expressão Popular.

Godoy, A. S. (1995). Introdução à pesquisa qualitativa e suas possibilidades. RAE - Revista de Administração de Empresas, 35(2), 5763.

Kolling, E. J., Nery, I., \& Molina, M. C. (1999). Por uma educação básica do campo (memória). Brasília: Articulação Nacional por uma Educação do Campo.

Nunes, K. C. S. (2016). Cenário da educação do Campo no Estado do Tocantins. Espaço do Currículo, 9(2), 328-340.

Oliveira, L. M. T., \& Campos, M. (2012). Educação Básica do Campo. In Caldart, R. S., Pereira, I. B., Alentejano, P., \& Frigotto, G. (Orgs.). Dicionário da Educação do Campo. Rio de Janeiro,
São Paulo: Escola Politécnica de Saúde Joaquim Venâncio, Expressão Popular. Tocantins. (2012). Secretaria de Estado de Educação, Juventude e Esportes. Programa Circuito Campeão. Recuperado em 09 de novembro, 2016, de http://www.planalto.gov.br.

(2015). Secretaria de Estado de Educação, Juventude e Esportes. Censo Escolar da Educação Básica. Palmas.

Nobre, M. (2004). A Teoria Crítica. Rio de Janeiro: Jorge Zahar Editor.

Tapscott, D., \& Williams, A. D. (2006). Wikinomics. New York: Portfolio.

Vasconcelos, M. L. M. C., \& Brito, R. H. P. (2006). Conceitos de educação em Paulo Freire. Petrópolis: Vozes.

Venâncio, R. D. O. (2007). Difusão Metropolitana e Divulgação Científica. São Paulo: Plêiade.

Venâncio, R. D. O. (2010). Massificação e Jornalismo. (Dissertação de Mestrado). Universidade de São Paulo.

Venâncio, R. D. O. (2013). Jogo Lógico e a Gramática do Rádio. (Tese de Doutorado). Universidade de São Paulo.

Wright Mills, C. (1981). A Elite do Poder. Rio de Janeiro: Zahar.

\footnotetext{
i O termo "Escolas Rurais" aponta para algo não superado na discussão do processo educativo de espaços "não urbanos" e o uso do termo educação do campo ou escolas do campo, formula a possibilidade de carregar a perspectiva de uma educação tal como se anuncia nas Diretrizes Operacionais para a Educação Básica nas escolas do campo.
} 
ii Conforme IBGE (2016), a população estimada do Estado do Tocantins corresponde a 1.532.902 habitantes.

iii Por mais que haja a discussão e defesa de uma Educação do Campo, com escolas do campo, o que ainda muito se encontra é uma educação para o meio rural, repleta de escolas rurais, ou seja, de escolas distribuídas no campo, mas sem uma proposta de trabalho e organização (de infraestrutura física, de equipe de trabalho, calendário, modelo de ensino - alternância) que faça delas uma escola do e para o campo, emanada de suas necessidades e estruturada para contemplar a aprendizagem de saberes universais e sobre o local onde vivem os alunos.

iv A exemplo: Decreto $\mathrm{n}^{\mathrm{o}} 7.352$ de $04 / 11 / 10$ (dispõe sobre a política de educação do campo); Resolução CNE/CEB $\mathrm{n}^{\circ} 02$ de 28/04/2008 (estabelece diretrizes complementares, normas e princípios para o desenvolvimento de políticas públicas de atendimento da Educação Básica do Campo) e Resolução CNE/CEB $\mathrm{n}^{\circ} 01 \mathrm{de}$ 03/04/2002 (institui diretrizes operacionais para a educação básica nas escolas do campo).
Recebido em: 05/10/2016

Aprovado em: 19/10/2016

Publicado em: 13/12/2016

Como citar este artigo / How to cite this article / Como citar este artículo:

APA:

Santos, T. F., Vizolli, I., \& Stephani, A. D. (2016). Desvelando cercas: um olhar sobre a Educação do Campo no Sudeste do Tocantins. Rev. Bras. Educ. Camp., 1(2), 381401.

\section{ABNT:}

SANTOS, T. F.; VIZOLLI, I.; STEPHANI, A. D. Desvelando cercas: um olhar sobre a Educação do Campo no Sudeste do Tocantins. Rev. Bras. Educ. Camp., Tocantinópolis, v. 1, n. 2, p. 381-401, 2016. 